\title{
Successful treatment of a persistent duodenal fistula using the Amplatzer septal occluder
}

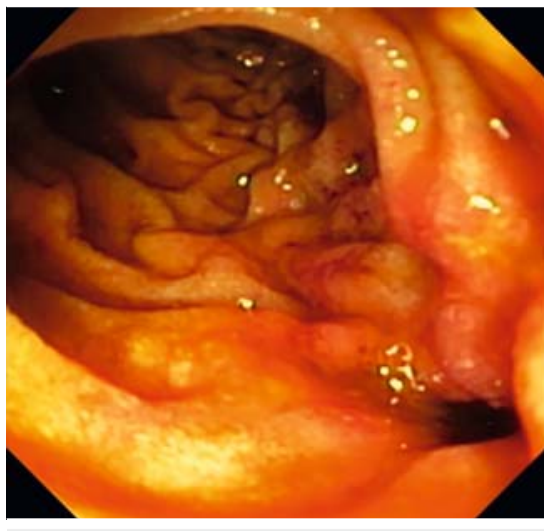

- Fig. 1 Endoscopic view of a duodenal cutaneous fistula in a 61-year-old man.

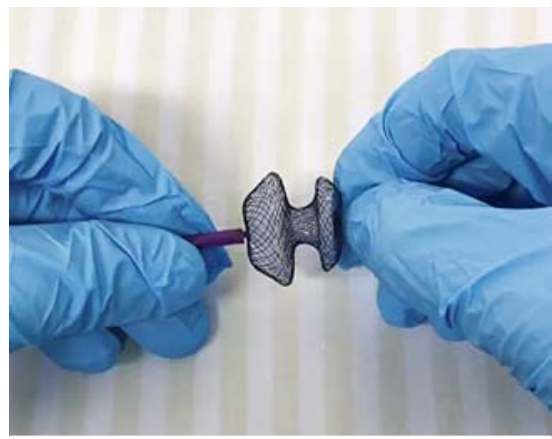

Fig. 2 Endoscopic introduction device fashioned by the present authors.

Duodenal fistula is a rare but serious complication of gastrointestinal surgery, abdominal trauma, and iatrogenic procedures in general [1]. It is most commonly seen in critically ill patients at elevated risk of death, and its treatment is associated with great challenges, including repeated episodes of recurrence [2]. Endoscopic closure methods are now becoming more reliable and are already being considered as first-line options in the management of this condition.

A 61-year-old man underwent ileocolectomy due to complicated appendicitis. He was referred to our institution and underwent a new procedure because of dehiscence of the ileocolic anastomosis. A new ileocolic anastomosis was per-

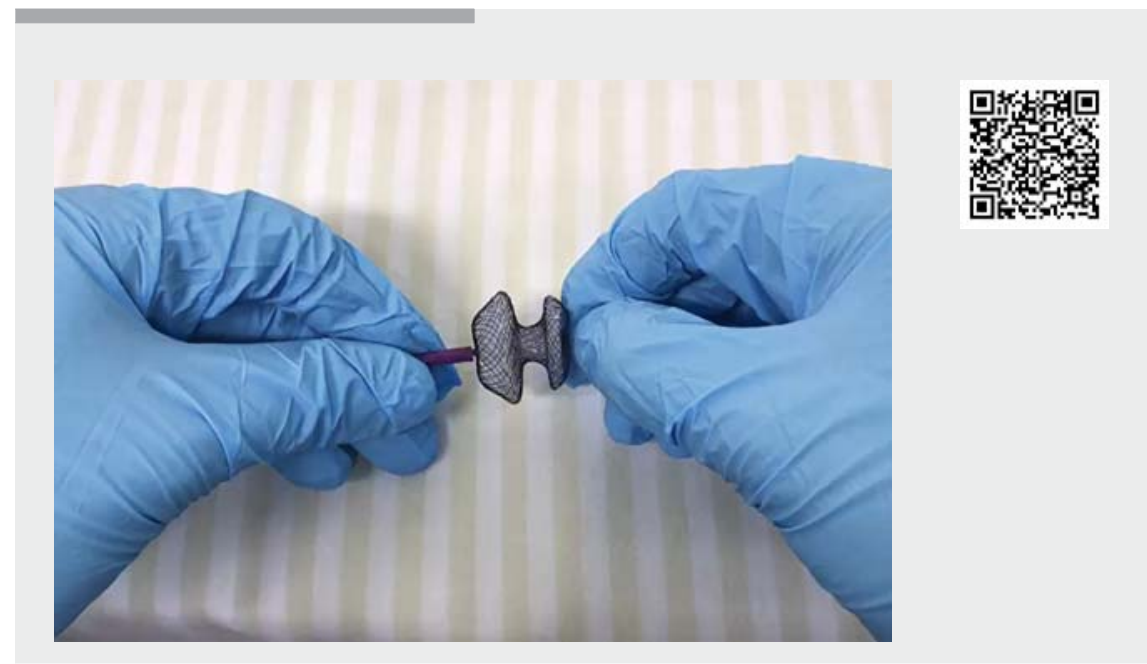

$\checkmark$ Video 1 Successful treatment of a persistent duodenal fistula using the Amplatzer septal occluder.

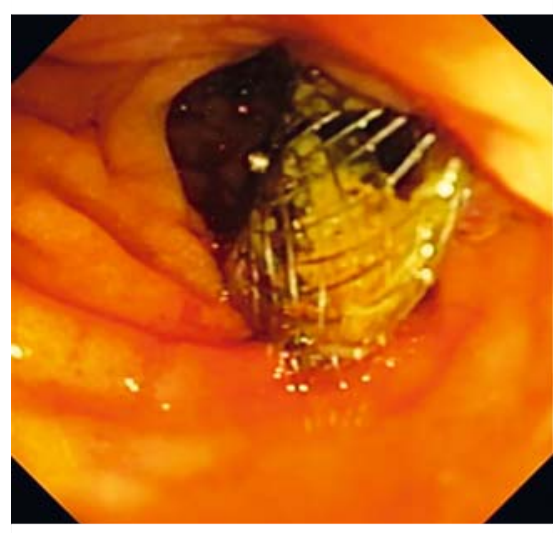

Fig. 3 Endoscopic view of the deployed Amplatzer septal occluder.

formed. After a few days, the presence of a duodenal cutaneous fistula associated with a large peritoneal collection became evident. The peritoneal collection was surgically drained, but the duodenal leak persisted.

The patient underwent an endoscopic closure attempt, performed with standard through-the-scope clips (TTSC). The procedure was unsuccessful, and the fistula showed signs of recanalization (> Fig.1). A second endoscopic proce-

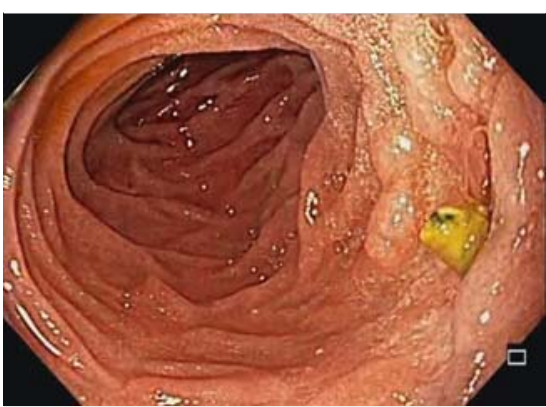

Fig. 4 Endoscopic view at follow-up 7 months after the procedure.

dure was performed, using the Amplatzer septal occluder (St. Jude Medical, St. Paul, Minnesota, USA). The Amplatzer is a self-expandable, double-disk occluder device developed for the endovascular treatment of persistent cardiac wall defects [3]. We fashioned an endoscopic introduction device using the external sheath of a 12-Fr biliary plastic stent and a pediatric biopsy forceps ( $>$ Video 1; - Fig. 2). The opening of the first flange was performed under fluoroscopic guidance, while the second flange (in the duodenal lumen) was deployed under endoscopic surveillance (> Fig.3). Con- 
trol fluoroscopy showed no contrast leak. After the procedure, the patient showed decreasing amounts of leakage through the external orifice of the fistula, received oral diet, and after 12 days was discharged. Endoscopic follow-up 7 months later showed the occluder in situ, partially grown into by the surrounding mucosa (\$ Fig.4). No recurrences were documented during this period.

\section{Endoscopy_UCTN_Code_TTT_1AO_2AI}

\section{Competing interests}

The authors declare that they have no conflict of interest.

The authors

Marco A. D’Assuncao, Fernando L. Mota, Fernando J. S. de Oliveira, Marília N. Ferreira, Mayra M. F. Guedes, Amanda M. B. Ziegler, Raul Cutait

Department of Digestive Endoscopy, Hospital Sírio-Libanês, São Paulo, Brazil
Corresponding author

\section{Fernando L. Mota, MD}

Department of Digestive Endoscopy, Hospital Sírio-Libanês, Rua Dona Adma Jafet, 91, São Paulo, Brazil

landerfernando@hotmail.com

\section{References}

[1] Boulougouri K, Theodoropoulos E, Karydas $G$ et al. Combined endoscopic and percutaneous treatment of a duodenocutaneous fistula using an Amplatzer septal occluder. Cardiovasc Intervent Radiol 2009; 32: 356360

[2] Willingham FF, Buscaglia JM. Endoscopic management of gastrointestinal leaks and fistulae. Clin Gastroenterol Hepatol 2015; 13: 1714-1721

[3] Odemis B, Beyazit Y, Torun S et al. Endoscopic closure of gastrocutaneous fistula with an Amplatzer septal occluder device. Therap Adv Gastroenterol 2015; 8: 239-242

\section{Bibliography}

Endoscopy 2021; 53: E311-E312

DOI 10.1055/a-1253-8101

ISSN 0013-726X

published online 8.10.2020

(c) 2020. Thieme. All rights reserved.

Georg Thieme Verlag KG, Rüdigerstraße 14,

70469 Stuttgart, Germany

\section{ENDOSCOPY E-VIDEOS}

https://eref.thieme.de/e-videos

回的 Endoscopy E-Videos is a free

然的 access online section, reporting on interesting cases and new

techniques in gastroenterological endoscopy. All papers include a high quality video and all contributions are freely accessible online.

This section has its own submission website at

https://mc.manuscriptcentral.com/e-videos 